\title{
A RESIDUAL-BASED POSTERIORI ERROR ESTIMATES FOR $h p$ FINITE ELEMENT SOLUTIONS OF GENERAL BILINEAR OPTIMAL CONTROL PROBLEMS
}

\begin{abstract}
ZULIANG LU
Abstract. In this paper, we investigate a residual-based posteriori error estimates for the $h p$ finite element approximation of general optimal control problems governed by bilinear elliptic equations. By using the $h p$ discontinuous Galerkin finite element approximation for the control and the $h p$ finite element approximation for both the state and the co-state, we derive a posteriori upper error bounds for the optimal control problems governed by bilinear elliptic equations in $L^{2}-H^{1}$ norms. We also give a posteriori lower error bounds for the error estimate of the optimal control problems. These estimates can be readily used for constructing a reliable adaptive finite element approximation for such optimal control problems.
\end{abstract}

Mathematics subject classification (2010): 49J20, 65N30.

Keywords and phrases: General bilinear optimal control problems, $h p$ finite element methods, adaptive finite element approximation, a residual-based posteriori error estimator.

\section{REFERENCES}

[1] I. BABUSKA AND M. SURI, The hp-version of the finite element method with quasiuniform meshes, RAIRO Math. Model. Numer. Anal., 21 (1987), pp. 199-238.

[2] I. BABUSKA AND M. SURI, The $p$ - and $h$ - $p$ version of the finite element method, an overview, Comput. Meth. Appl. Mech. Engrg., 80 (1990), pp. 5-26.

[3] I. Babuska, B. Guo And E. P. Stephan, The $h-p$ version of the finite element method, an overview, Comput. Meth. Appl. Mech. Engrg., 80 (1990), pp. 319-325.

[4] I. BABUSKA AND B. GUO, Approximation properties of the $h-p$ version of the finite element method, Comput. Meth. Appl. Mech. Engrg., 133 (1996), pp. 319-346.

[5] Y. CHEN, Superconvergence of mixed finite element methods for optimal control problems, Math. Comp., 77 (2008), pp. 1269-1291.

[6] Y. CHEN, Superconvergence of quadratic optimal control problems by triangular mixed finite elements, Int. J. Numer. Meth. Engng., 75 (2008), pp. 881-398.

[7] Y. CHEN AND Y. LiN, A posteriori error estimates for hp finite element solutions of convex optimal control problems, J. Comp. Appl. Math., 235 (2011), pp. 3435-3454.

[8] Y. CHEN AND W. LIU, A posteriori error estimates for mixed finite element solutions of convex optimal control problems, J. Comp. Appl. Math., 211 (2008), pp. 76-89.

[9] Y. CHEN AND Z. LU, Error estimates of fully discrete mixed finite element methods for semilinear quadratic parabolic optimal control problems, Comput. Methods Appl. Mech. Engrg., 199 (2010), pp. $1415-1423$.

[10] Y. CHEN AND Z. LU, Error estimates for parabolic optimal control problem by fully discrete mixed finite element methods, Finite Elem. Anal. Des., 46 (2010), pp. 957-965.

[11] Y. Chen, Z. Lu AND Y. HuAng, Superconvergence of triangular Raviart-Thomas mixed finite element methods for bilinear constrained optimal control problem, Comp. Math. Appl., 66 (2013), pp. $1498-1513$.

[12] Y. Chen, N. YI, AND W. LIU, A Legendre-Galerkin spectral method for optimal control problems governed by elliptic equations, SIAM J. Numer. Anal., 46 (2008), pp. 2254-2275. 
[13] F. S. FALK, Approximation of a class of optimal control problems with order of convergence estimates, J. Math. Anal. Appl., 44 (1973), pp. $28-47$.

[14] D. A. French AND J. T. King, Approximation of an elliptic control problem by finite element method, Numer. Funct. Anal. Optim., 12 (1991), pp. 299-314.

[15] B. GUO AND W. CAO, An additive schwarz method for the $h p$ version of the finite element method in three dimensions, SIAM J. Numer. Anal., 35 (1998), pp. 632-654.

[16] W. LIU, Adaptive multi-meshes in finite element approximation of optimal control, Contemp. Math., 383 (2005), pp. 113-132.

[17] R. LI, W. LIU, H. MA, AND T. TANG, Adaptive finite element approximation for distributed elliptic optimal control problems, SIAM J. Control Optim., 41 (2002), pp. 1321-1349.

[18] J. L. Lions, Optimal control of systems governed by partial differential equtions, Springer, Berlin, 1971.

[19] W. LIU AND N. YAN, A posteriori error estimates for some model boundary control problems, J. Comp. Appl. Math., 120 (2000), pp. 159-173.

[20] W. LIU AND N. YAN, A posteriori error estimates for convex boundary control problems, SIAM J. Numer. Anal., 39 (2001), pp. 73-99.

[21] W. LIU AND N. YAN, Adaptive finite element methods for optimal control governed by PDEs, Science Press, Beijing, 2008.

[22] Z. LU AND Y. CHEN, A posteriori error estimates of triangular mixed finite element methods for semilinear optimal control problems, Adv. Appl. Math. Mech., 1 (2009), pp. 242-256.

[23] Z. LU AND Y. CHEN, A posteriori error estimates of lowest order Raviart-Thomas mixed finite element methods for bilinear optimal control problems, Numer. Anal. Appl., 12 (2009), pp. 74-86.

[24] Z. LU, Y. CHEN AND W. ZHENG, A posteriori error estimates of lowest order Raviart-Thomas mixed finite element methods for bilinear optimal control problems, East Asia J. Appl. Math., 2 (2012), pp. $108-125$.

[25] J. M. MELENK, $h p$-interpolation of nonsmooth functions and an application to $h p$-a posteriori error estimation, SIAM J. Numer. Anal., 43 (2005), pp. 127-155.

[26] J. M. MelenK AND B. Wohlmuth, On residual-based a posteriori error estimation in hp-FEM, Advances in Comp. Math., 15 (2001), pp. 311-331.

[27] D. Tiba AND F. TRoltzsch, Error estimates for the discretization of state constrained convex control problems, Numer. Funct. Anal. Optim., 17 (1996), pp. 1005-1028. 